\title{
Morphology and Thermal Properties of Core-Shell PVA/PLA Ultrafine Fibers Produced by Coaxial Electrospinning
}

\author{
Raquel P. Gonçalves, Flavia F. F. da Silva, Paulo H. S. Picciani, Marcos L. Dias* \\ Institute of Macromolecules, Federal University of Rio de Janeiro, Rio de Janeiro, Brazil \\ Email: "mldias@ima.ufri.br
}

Received 19 January 2015; accepted 10 February 2015; published 15 February 2015

Copyright (C) 2015 by authors and Scientific Research Publishing Inc.

This work is licensed under the Creative Commons Attribution International License (CC BY).

http://creativecommons.org/licenses/by/4.0/

\begin{abstract}
Coaxial electrospinning process was used to produce biodegradable membranes made of coreshell fibers of a poly(lactic acid) (PLA) shell and a poly(vinyl alcohol) (PVA) core. Scanning electron microscopy analyses of these structures showed that the PLA shell can present certain porosity depending on the process condition. FTIR-ATR and contact angle measurements also suggested imprisonment of the PVA core within the PLA shell. This type of structure was also confirmed by means of transmissions electron microscopy. The morphology of these fibers was dependent on the flow rate of both core and shell solutions, and homogeneous and smooth surface was only attained when the flow rate of the external PLA solution was 4 times the flow rate of the internal PVA solution. The increase in the PLA solution flow rate increases the diameter of the core-shell fiber which reaches up to $1.7 \mu \mathrm{m}$. Nevertheless, fibers with smaller average diameter could also be produced $(200 \mathrm{~nm})$. These core-shell fibers presented improved hydrophilicity as compared with monolithic PLA fibers.
\end{abstract}

Keywords

Core-Shell Fibers, Electrospinning, Poly(Lactic Acid), Poly(Vinyl Alcohol)

\section{Introduction}

Electrospinning is a simple method to produce mats of fibers with diameter which can reach the nanometer scale. The technique is based on the application of an electrical field in a polymer solution, and, nowadays, it is considered one of the most efficient techniques to fabricate high performance nanofibers mats, with distinct advantages like high surface area in relation to volume and porosity. Changing adequately the process parameters, it is

\footnotetext{
*Corresponding author.
}

How to cite this paper: Gonçalves, R.P., da Silva, F.F.F., Picciani, P.H.S. and Dias, M.L. (2015) Morphology and Thermal Properties of Core-Shell PVA/PLA Ultrafine Fibers Produced by Coaxial Electrospinning. Materials Sciences and Applications, 6, 189-199. http://dx.doi.org/10.4236/msa.2015.62022 
possible to obtain fibers with different diameters and structures according to a specific application [1] [2]. Recently, advances in the electrospinning technique have allowed the production of different fibrillar structures, for example, fibrous tubes [3], core-shell nanofibers [4] and membranes with different compositions [5].

In order to obtain fibers with different core-shell compositions, two or more polymeric solutions may be used. These solutions are, however, injected from two different coaxial capillary channels, resulting in a structure with two distinct environments [6].

The electrospinning technique has grown particularly due to the possibility of combining different materials in a single system, resulting in a large interest in potential application as membranes for filtration, scaffolds for tissue engineering and systems for encapsulation of active compounds [7] [8]. Figure 1 shows a schematic representation of different fiber morphologies that can be obtained when coaxial eletrospinning is employed, for example, coaxial fibers made of a polymeric material shell and a non-electrospinnable material core (A); coaxial fibers made of two different electrospinnable materials (B); and tubular fibers prepared by removal of the inner material after coaxial electrospinning (C).

Coaxial electrospun fibers have been shown to be useful in gene delivery [9], drug delivery [10], bioactive molecules delivery [11] [12] and sensors [13], for example.

In this study, we investigate how electrospinning parameters can affect coaxial fibers characteristics. We present results of an interesting system formed by core-shell fibers constituted by poly(lactic acid) (PLA) and poly(vinyl alcohol) (PVA), and its morphology and thermal characterization. The chosen polymer for the shell was PLA, a hydrophobic polymer whose biodegradation results in decomposition products that can be eliminated from the body by the metabolic pathways [14] [15]. PVA, a hydrophilic semi-crystalline polymer was used for the formation of the internal structure of the fiber (core) [16]. The effects of polymer solution flow rate used in the coaxial electrospinning, on formation of the core as well as the structure and morphology of the electrospun fibers were investigated.

\section{Experimental}

\subsection{Materials}

PolylactideIngeo Biopolymer 3251D $(\mathrm{Mw}=160,000)$ was acquired from Nature Works. Poly(vinyl alcohol) 87\% - 90\% hydrolyzed, average molwt 30,000 - 70,000, chloroform, dimethylformamide (DMF) and ethanol 99.8\% were obtained from Sigma Aldrich. All polymers and solvents were used as received.

\subsection{Coaxial Electrospinning}

Polymer solutions were previously prepared at room temperature under magnetic stirring. PVA solution (15\% $\mathrm{wt} / \mathrm{vol}$ ) was prepared by using water/ethanol $=8 / 2$ as solvent and PLA solution $(18 \% \mathrm{wt} / \mathrm{vol})$ was prepared using mixture of chloroform/DMF $=8 / 2$ as solvent.

Electrospinning was carried out in a standard electrospinning apparatus with a KD Scientific syringe pump (KDS Model 100), a High Voltage DC Power Supply PS/FC60P02.0-11 Glassman High Voltage and a metallic plate as collector (Figure 2). Polymer solutions ( $5 \mathrm{~mL}$ ) were pumped through a Rheodyne 22GA (ID = $0.7 \mathrm{~mm}$ )
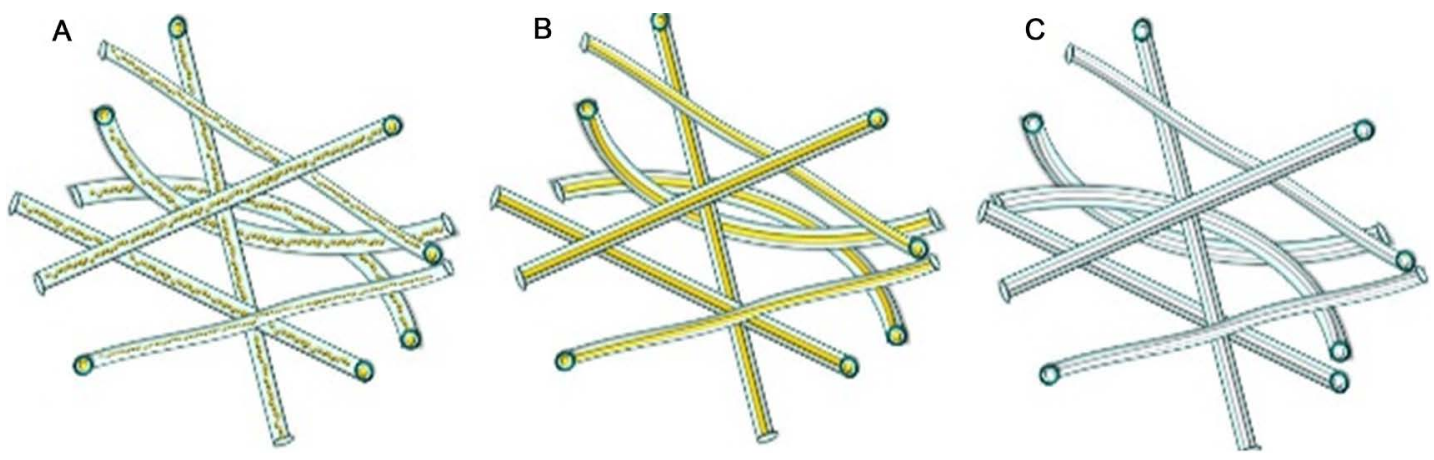

Figure 1. Schematic representation of fibers made by coaxial electrospinning: (A) Coaxial fibers made of a polymeric material shell and a non-electrospinnable material core; (B) Coaxial fibers made two different electrospinnable materials; and (C) Tubular fibers prepared by removal of the inner material after coaxial electrospinning. 
Luer tip needle. The fibers were collected in an aluminum plate target as randomly oriented nonwoven mats. For the coaxial electrospinning, a device designed with coaxial needles formed by an internal needle with ID $=0.5$ $\mathrm{mm}$ and an external needle with ID $=0.84 \mathrm{~mm}$ were employed. This device was coupled to the equipment. Experiments were carried out using $20 \mathrm{kV}$ as voltage at room temperature. The needle-plate distance (D) was set from 10 to $20 \mathrm{~cm}$. Table 1 resumes the conditions of electrospinning used for preparation of PLA, PVA and PVA/PLA core-shell fibers.

\subsection{Monolithic and Core-Shell Fibers Characterization}

The morphology of monolithic and core-shell fibers was analyzed by scanning electron microscopy (SEM) in a JEOL JSM-5300 and Quanta $450 \mathrm{~F}$ microscopes at $15 \mathrm{kV}$. All samples were Au-coated. Selected images at different magnifications were considered as representative of the whole sample. Fibers average diameters and diameters distribution were determined from the images using the Size Meter software.

The coaxial structure was observed by means of transmission electron microscopy (TEM). For observation, samples were prepared by deposition of a thin layer of the electrospun fibers directly over a copper grid covered with carbon. Iron particles were added to the PVA solution prior the electrospinning process in order to obtain contrast between the two types of polymers that form the fibers.

Attenuated Total Reflection Fourier Transform Infrared Spectroscopy (FTIR-ATR) was performed in a Varian Excalibur 3100 FT-IR spectrophotometer in the ATR mode by using a Pike Miracle ATR sampler accessory. A small amount of mat of fibers was placed on the crystal and pressed, ensuring good contact between the crystal and samples.

Measurements of contact angle of the monolithic and core-shell fibers were evaluated using deionized water as solvent. Contact angles were measured in a Dataphysics OCA-20 automatic goniometer, immediately after 32 microliters water droplet freely fell over the fiber mat surface. For each mat, it was considered the average result from 3 measurements done in three different points of the membrane surface.

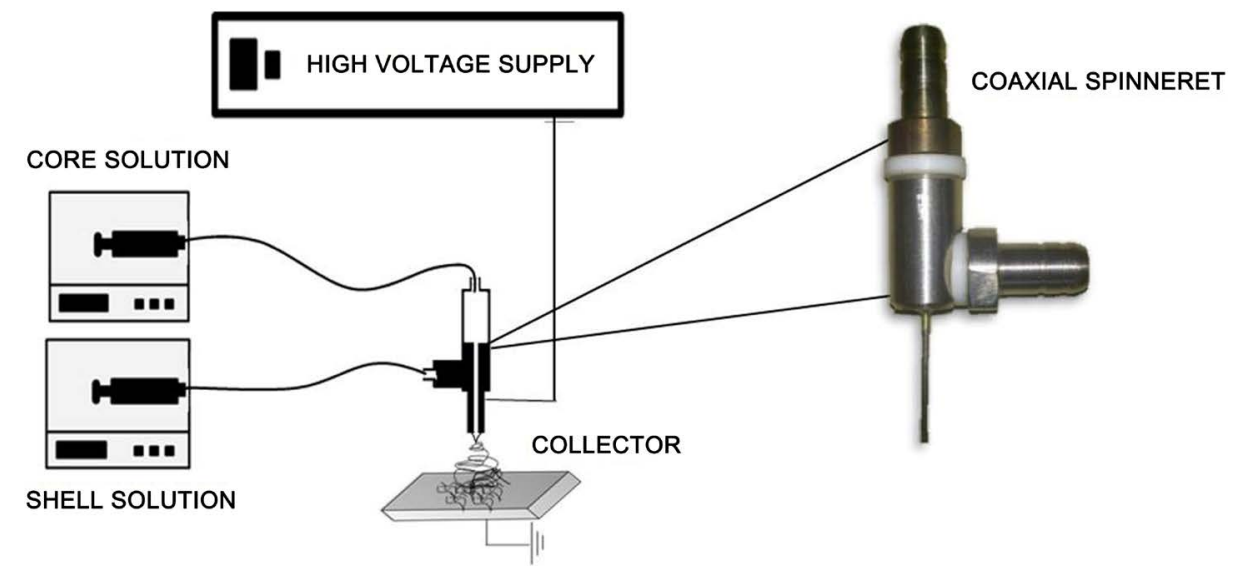

Figure 2. Schematic representation of an electrospinning apparatus with the coaxial spinneret.

Table 1. Conditions of electrospinning of PLA, PVA and PVA/PLA core-shell fibers ${ }^{a}$.

\begin{tabular}{cccc}
\hline & & Electrospinning flow rate $(\mathrm{mL} / \mathrm{h})$ & \\
Fiber & Core & Shell \\
\cline { 2 - 3 } PVA & 0.3 & - \\
PVA & 0.15 & 0.15 \\
& 0.15 & 0.3 \\
\hline
\end{tabular}

\footnotetext{
${ }^{\mathrm{a}}$ Applied voltage $=20 \mathrm{kV}$; needle tip-collector distance $=13 \mathrm{~cm}$.
} 
Thermal properties of the monolithic and core-shell fibers were evaluated by thermogravimetry (TGA) in a TA Instruments model TGA-7 and by calorimetry in a differential scanning calorimeter in a TA Instruments DSC model Q 1000. For TGA analyses, a piece of core-shell membrane was cut and introduced in the equipment panel. The experiments were performed from $25^{\circ} \mathrm{C}$ to $700^{\circ} \mathrm{C}$ at a heating rate of $10^{\circ} \mathrm{C} / \mathrm{min}$ under nitrogen flow of $60 \mathrm{~mL} / \mathrm{min}$. For the DSC analyses, a sample of the fiber mat was first heated from $30^{\circ} \mathrm{C}$ to $200^{\circ} \mathrm{C}$ at $10^{\circ} \mathrm{C} / \mathrm{min}$ and then cooled at $10^{\circ} \mathrm{C} / \mathrm{min}$ to room temperature, followed by a second heating at $10^{\circ} \mathrm{C} / \mathrm{min}$. Degree of crystallinity of PLA was determined considering $106 \mathrm{~J} / \mathrm{g}$ as standard melting enthalpy and cold crystallization during heating.

\section{Results and Discussions}

\subsection{Morphology of Monolitic and Core-Shell Fibers}

Two of the factors that most affect the production of homogeneous and flawless defect-free fibers are surface tension and solvent evaporation rate, both regulated by polymer-solvent interactions. The addition of a nonsolvent of PVA, such as ethanol, to an aqueous PVA solution decreases the surface tension and viscosity of the solution, which enhance the possibility of forming beaded fibers [17] [18]. On the other hand, ethanol evaporates faster than pure water. When solvent does not evaporate before fibers deposition, the jets can coalesce themselves forming mats with different morphologies. So, balance between surface tension reduction and solvent evaporation speed must be achieved in order to obtain perfect fibers [5].

PLA solutions were prepared using chloroform due to its good performance in dissolving this polymer, but the solution could not be electrospun smoothly due to its low conductivity and dielectric constant. Thus, DMF, which has considerable conductivity and dielectric constant can be added to chloroform to cover the shortage of single $\mathrm{CHCl}_{3}$. Then, these two solvents were mixed at $\mathrm{CHCl}_{3} / \mathrm{DMF}=8 / 2$ volume ratio to dissolve PLA and produce electrospinnable solutions [19]-[21].

Figure 3 shows the images of monolithic fibers obtained from electrospinning experiments carried out at 20 $\mathrm{kV}$ and $13 \mathrm{~cm}$ of distance between needle tip and collector. These monolithic fibers were successfully produced with $15 \% \mathrm{w} / \mathrm{v}$ PVA solution (8:2 water:ethanol) and $0.15 \mathrm{~mL} / \mathrm{h}$ flow rate, and $18 \% \mathrm{w} / \mathrm{v}$ PLA solution (8:2 $\mathrm{CHCl}_{3}: \mathrm{DMF}$ ) at $0.30 \mathrm{~mL} / \mathrm{h}$. PVA and PLA monolithic nanofibers were obtained with average diameters of 230 $\mathrm{nm}$ and $450 \mathrm{~nm}$, respectively (Figure 3(A) and Figure 3(B)). Porous formation can be seen on PLA fiber surface as the result of fast solvent evaporation. During the path from the needle tip to the collector, the jet is surrounded by atmosphere moisture that causes fibers cooling and small droplets of solvent onto the jet surface. Later those droplets evaporate, leaving a mark in form of spots [22] [23].

By using the device constituted by two coaxial needles (Figure 1), two components can be fed simultaneously to form a core-shell structure. An $18 \%$ w/v PLA solution was fed to the external needle with $0.15,0.3$ or 0.6 $\mathrm{mL} / \mathrm{h}$ flow rate while a $15 \% \mathrm{w} / \mathrm{v}$ PVA solution was used in the internal needle with flow rate of $0.15 \mathrm{~mL} / \mathrm{h}$. The electrical field and flow rate are the main parameters that can affect the formation of both core and shell in this process [24].

PVA/PLA core-shell fibers were obtained with different combination of flow rates, as indicated in Table 1. Only the fibers obtained with internal flow rate 4 times lower than the external flow rate showed morphology free of defects. Curiously, in this condition the higher diameter was obtained, probably due to the higher feed flow rate of the external PLA layer $(0.6 \mathrm{~mL} / \mathrm{h})$.

Core-shell fibers obtained with the same flow rate $(0.15 \mathrm{~mL} / \mathrm{h})$ for both internal and external solutions were not smooth with heterogeneous size distribution, indicating that two different types of monolithic fibers could be produced from two independent and simultaneous jets, probably due to the rupture of the external jet. Better results were achieved when the external flow rate was at least the double of the internal flow rate (0.3 and 0.15 $\mathrm{mL} / \mathrm{h}$ ), indicating that this condition resulted in more stability of the external jet, but the fibers were not homogeneous yet. When an external flow rate were four times greater than the internal flow $(0.6$ and $0.15 \mathrm{~mL} / \mathrm{h})$, the fibers diameters were higher, but the fibers presented homogeneous distribution.

\subsection{Core-Shell Fibers Structure}

Although scanning electron microscopy is a powerful technique to characterize size, shape and structure of materials, when using backscattered electrons only the surface of samples can be evaluated [25] [26]. However, SEM analyses of fibers obtained by coaxial electrospinning of PLA and PVA solutions showed that some fibers presented cracks of the PLA shell, exposing the internal PVA fiber, as shown in Figure 4. The image shows that, 

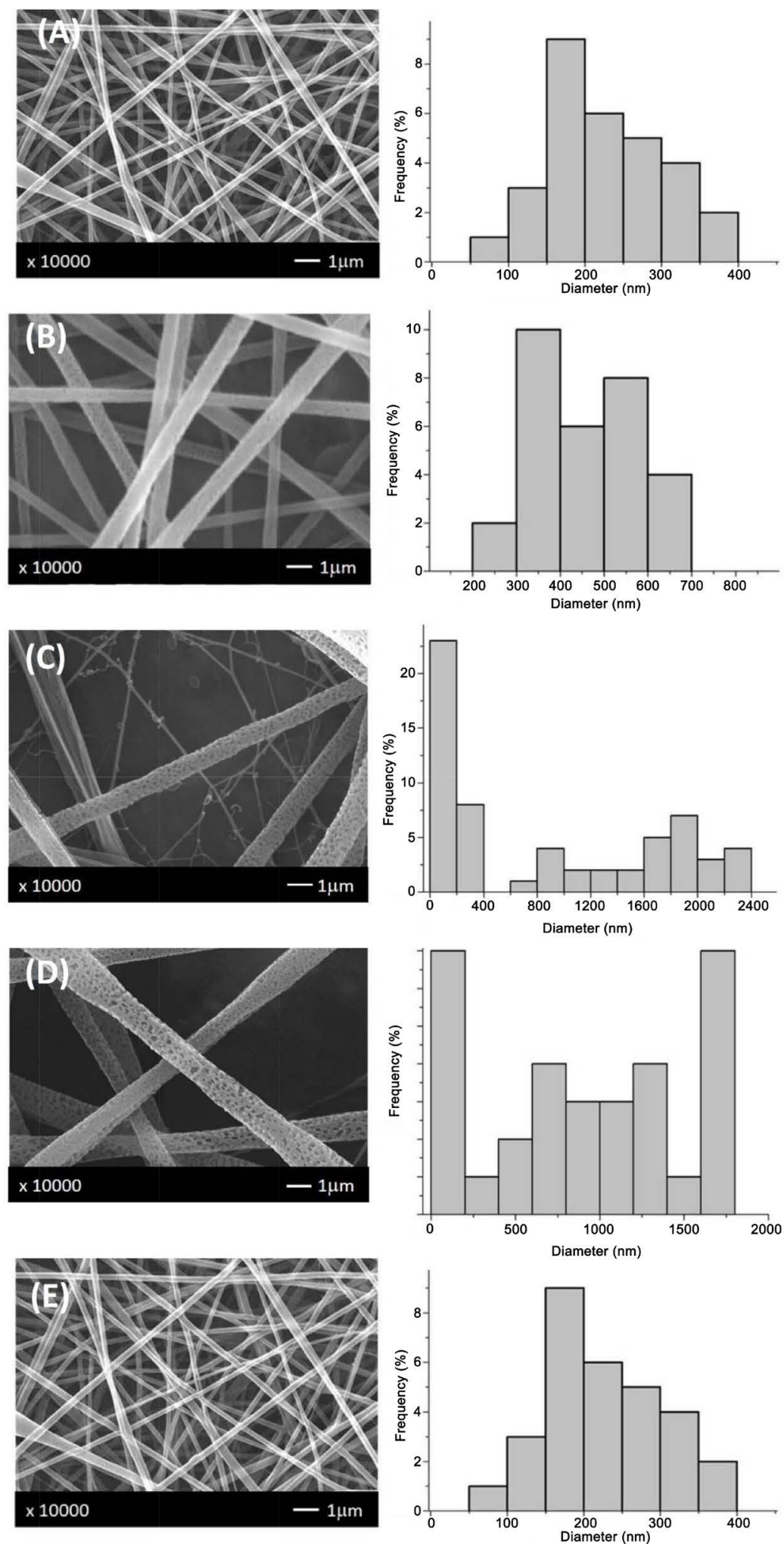

Figure 3. SEM images and size distribution of (A) monotlithic fibres of PVA obtained with $0.15 \mathrm{~mL} / \mathrm{h}$ flow rate; (B) monolithic fibers of PLA obtained with $0.3 \mathrm{~mL} / \mathrm{h}$ flow rate; (C) PVA/PLA core-shell fibers obtained with $0.15 \mathrm{~mL} / \mathrm{h}$ for both solutions; (D) coaxial fibers of PLA shell and PVA core obtained with 0.3 and $0.15 \mathrm{~mL} / \mathrm{h}$, respectively; and (E) coaxial fibers of PLA shell and PVA core obtained with 0.6 and $0.15 \mathrm{~mL} / \mathrm{h}$, respectively. 


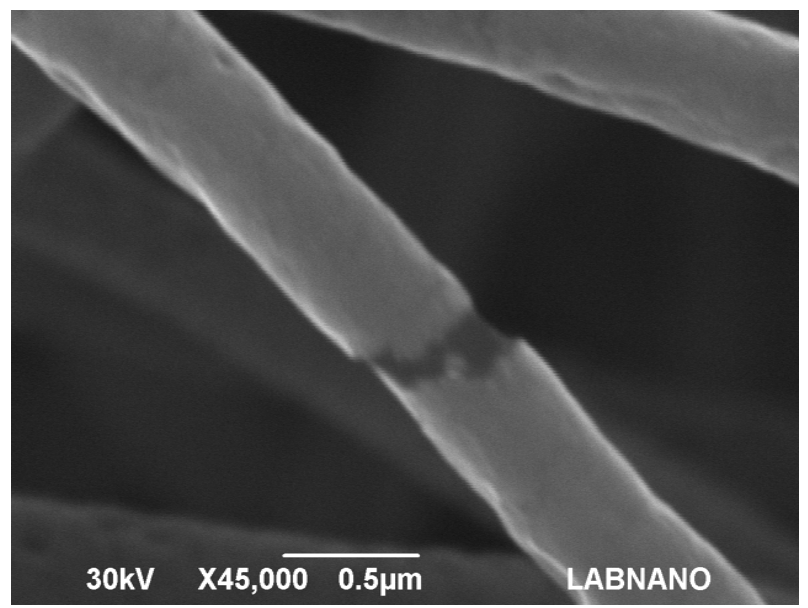

Figure 4. SEM images of a crackof PLA shell exposing the PVA core in a fiber produced from a $18 \% \mathrm{w} / \mathrm{v}$ PLA solution at $0.6 \mathrm{~mL} / \mathrm{h}$ and $15 \% \mathrm{w} / \mathrm{v}$ PVA solution at $0.3 \mathrm{~mL} / \mathrm{h}$.

in the electrospinning condition used the core of the fiber presented diameter significantly higher than the thickness of the PLA shell.

FTIR-ATR is animportant spectroscopic technique used to investigate the molecular and structural properties of polymers [27] [28]. In this work we use this technique to evaluate the surface composition of the fibers obtained by coaxial electrospining. Figure 5 shows the surface FTIR spectra (ATR mode) of PVA and PLA monolithic fibers as well as PVA-PLA core-shell fibers. PVA monolithic fibers presented the typical bands of hydroxyl groups at $3200-3600 \mathrm{~cm}^{-1}$, which cannot be seen in the core-shell fibers, indicating absence of this polymer on the surface of the fibers. This was an additional evidence of the core-shell structure of the fibers.

Figure 6 presented the contact angles of membranes formed by monolithic of PLA and PVA and core-shell fibers obtained at different PVA aqueous core solution flow rates. These contact angles were measured also to evaluate the core-shell structure by considering the difference of hydrophilicity of both polymers. As PLA is a highly hydrophobic polymer, its presence in the external layer of the fiber arouses the decrease in the membrane hydrophilicity. PVA membranes showed a contact angle of $39.2^{\circ}$ and PLA $113.6^{\circ}$. On the other hand, the membranes formed by core-shell fibers presented contact angles between $61^{\circ}$ and $82^{\circ}$. These results agree with microscopy results, once they suggest the presence of two distinct phases in the structure of the fibers and the wrapping of PVA core by a PLA shell. The decrease in the contact angle can be attributed to presence of small pores in the PLA shell that allow the increase in the hydrophilicity by the inner phase which may still contain residual water.

The interface between the PLA shell and the PVA core could be observed by TEM images (Figure 7). The contrast difference between core and shell was obtained by addition of iron to the PVA solution before the electrospinning process. It seems that the PVA solution is restricted to the central part of the PLA fiber, clearly showing a two-phase structure. In this two typical examples, one of the fibers with external diameter of $1.7 \mu \mathrm{m}$ showed the internal PVA phase diameter of $0.3 \mu \mathrm{m}(300 \mathrm{~nm})$ and a fiber with external diameter of $1.1 \mu \mathrm{m}$ presented the PVA core phase with diameter of $0.6 \mu \mathrm{m}(600 \mathrm{~nm})$.

\subsection{Thermal Properties of Core-Shell Fibers}

Thermal behavior of monolithic PVA and PLA fibers and PVA-PLA core-shell fibers was investigated by TGA and DSC.

Figure 8 shows TGA traces obtained by heating fibers from room temperature to $700^{\circ} \mathrm{C}$ under nitrogen atmosphere. PLA monolithic fibers showed only one stage of weight loss with on set at $305^{\circ} \mathrm{C}$ and maximum decomposition rate at $344^{\circ} \mathrm{C}$, which can be attributed to chain scission. PVA monolithic fibers presented, in addition to water lost at temperatures below $100^{\circ} \mathrm{C}$, two main stages of weight loss with maximum decomposition rate at $311.5^{\circ} \mathrm{C}$ (chain-stripping due to removal of water molecules, i.e., dehydration of the PVA chains) and $434^{\circ} \mathrm{C}$ (chain scission and decomposition) [29]. The loss of residual water in these PVA fibers was around 5 


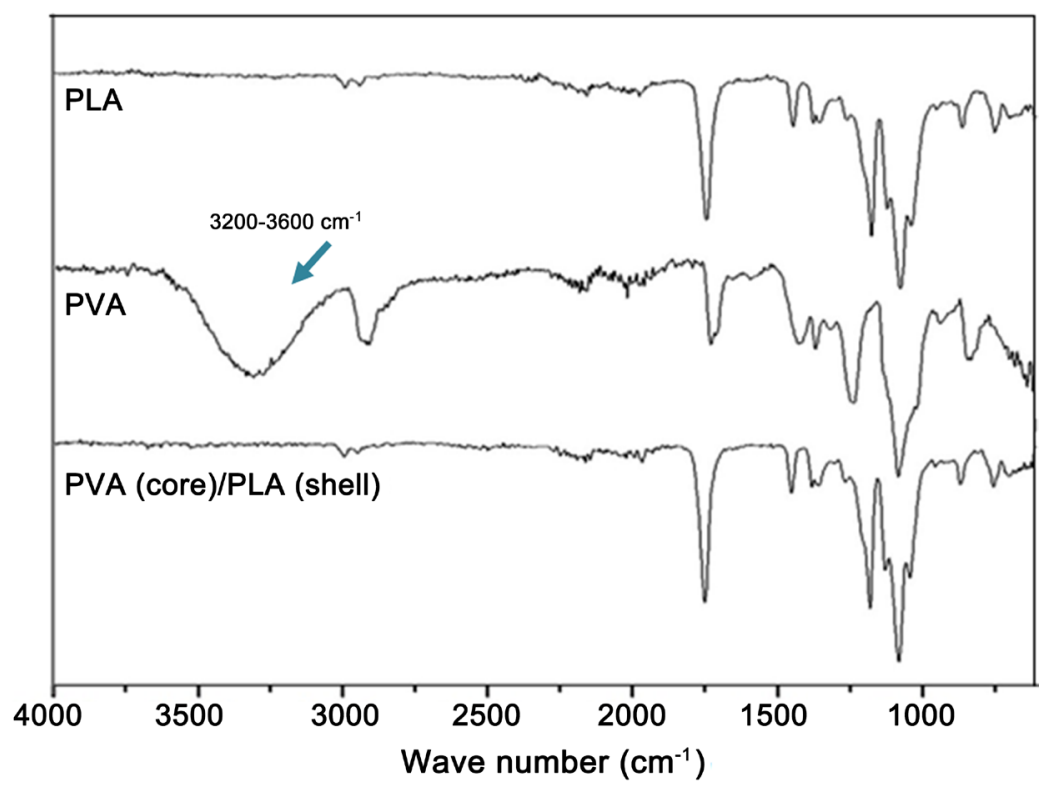

Figure 5. FTIR spectra (ATR mode) of monolithic PVA and PLA and PVA/PLA core shell fibers.

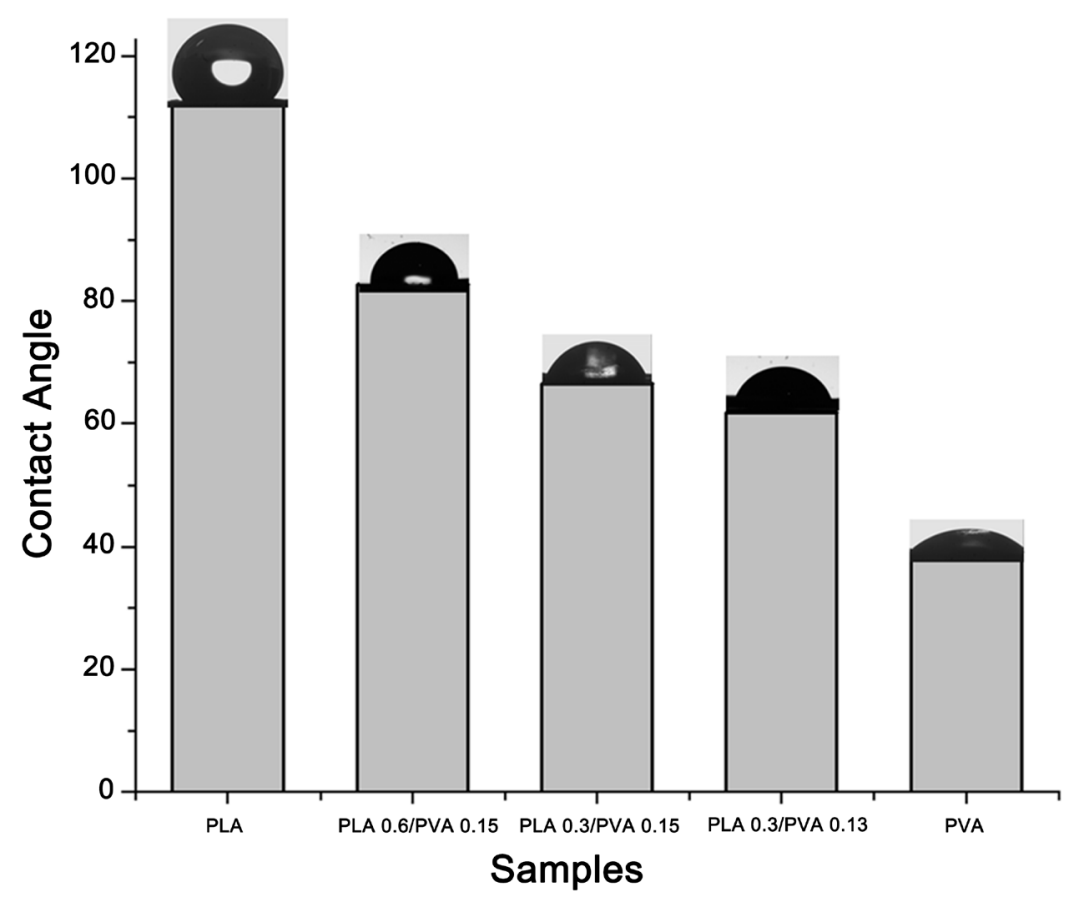

Figure 6. Contact angles of monolithic PVA and PLA and PVA/PLA core shell fibers.

wt\%. Like PLA monolithic fibers, PVA-PLA core-shell fibers showed also two stages of weight loss, in addition to moisture loss. These main weight losses appeared at $318^{\circ} \mathrm{C}$ and $437^{\circ} \mathrm{C}$. Surprisingly, these PVA-PLA coreshell fibers presented a significant lower moisture lost before $100^{\circ} \mathrm{C}$ (about $1 \mathrm{wt} \%$ ), suggesting that, if the amount of PVA solution water evaporated during the electrospinning process was not total as expected, this residual water in the PVA core, probably higher than $1 \mathrm{wt} \%$, is only lost after the PLA decomposition, overlapping the intense weight loss observed at $318^{\circ} \mathrm{C}$. Thus, this weigh loss observed at $318^{\circ} \mathrm{C}$ is probably the result of different processes (chain scission and trapped water vaporization). We expected to quantify the amount of water remaining in the PVA core of the fibers by using TGA analyses, but this behavior did not allow this quantification. 
Figure 9 shows the first heating run DSC traces of monolithic fibers (PVA and PLA) and PVA-PLA coreshell fibers. The first heating run was used because it could give an idea about morphology and crystalline structure considering the fiber formation history. Monolithic PVA fibers showed two endothermic events: a broad one at temperatures between $80^{\circ} \mathrm{C}$ and $150^{\circ} \mathrm{C}$ attributed to moisture lost, and another one at about $184^{\circ} \mathrm{C}$. The broad endothermic event of moisture lost overlaps the glass transition temperature $\left(\mathrm{T}_{\mathrm{g}}\right)$ which can only be seen in the second heating run of the fiber $\left(\mathrm{T}_{\mathrm{g}}=69^{\circ} \mathrm{C}\right)$. The first heating of PLA monolithic fibers showed all transitions usually observed for semi-crystalline PLA, with a $\mathrm{T}_{\mathrm{g}}$ at $55^{\circ} \mathrm{C}$, a cold crystallization $\left(\mathrm{T}_{\text {cc }}\right.$ ) at $90.9^{\circ} \mathrm{C}$ and melting temperature $\left(\mathrm{T}_{\mathrm{m}}\right)$ at $152.9^{\circ} \mathrm{C}$. When the first run DSC trace of PVA-PLA core-shell fibers is analyzed, a curve similar to that of monolithic PVA fibers was observed, indicating that some crystallization of PLA shell took place during the eletrospinning process. Inai [30] has reported that eletroctrospinning of PLLA under certain condition generate amorphous nanofibers. However, the results obtained in this work showed that the crystallization behavior during electrospinning process may be dependent on the PLA type and electrospinning condition. Under the conditions used in this work it was possible to obtain core-shell fibers in which the PLA shell is a moderate crystalline phase with degree of crystallinity around $11.8 \%$, according DSC.

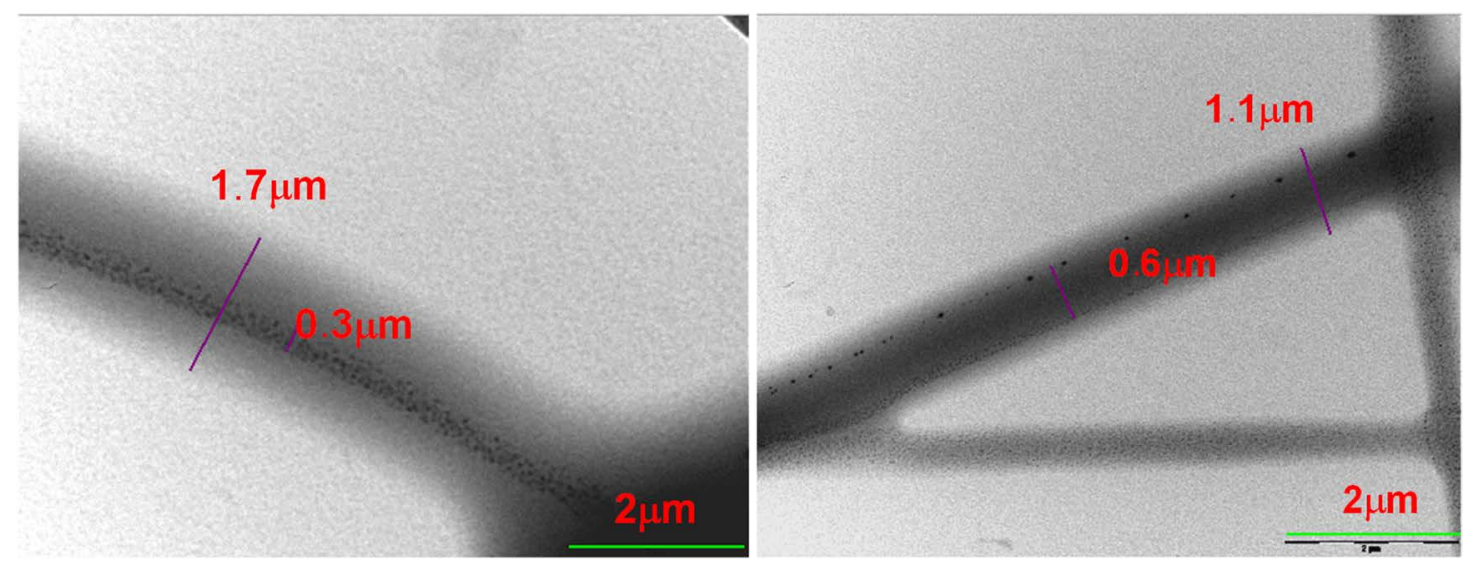

Figure 7. TEM images of core-shell fibers produced with PLA $18 \% \mathrm{w} / \mathrm{v}$ shell solution and PVA $15 \%$ w/v core solution, using both flow rates at $0.15 \mathrm{~mL} / \mathrm{h}$.

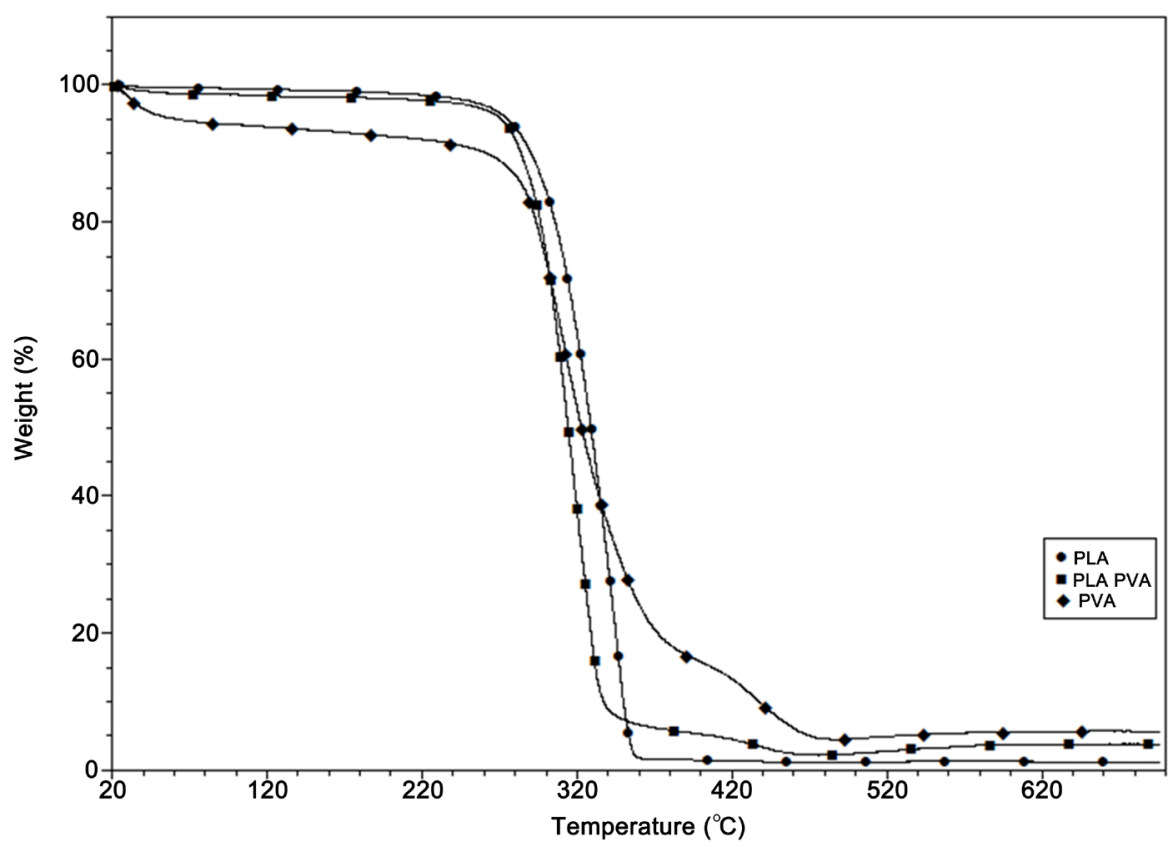

Figure 8. TGA traces of monolithic PVA and PLA and PVA/PLA core shell fibers. 


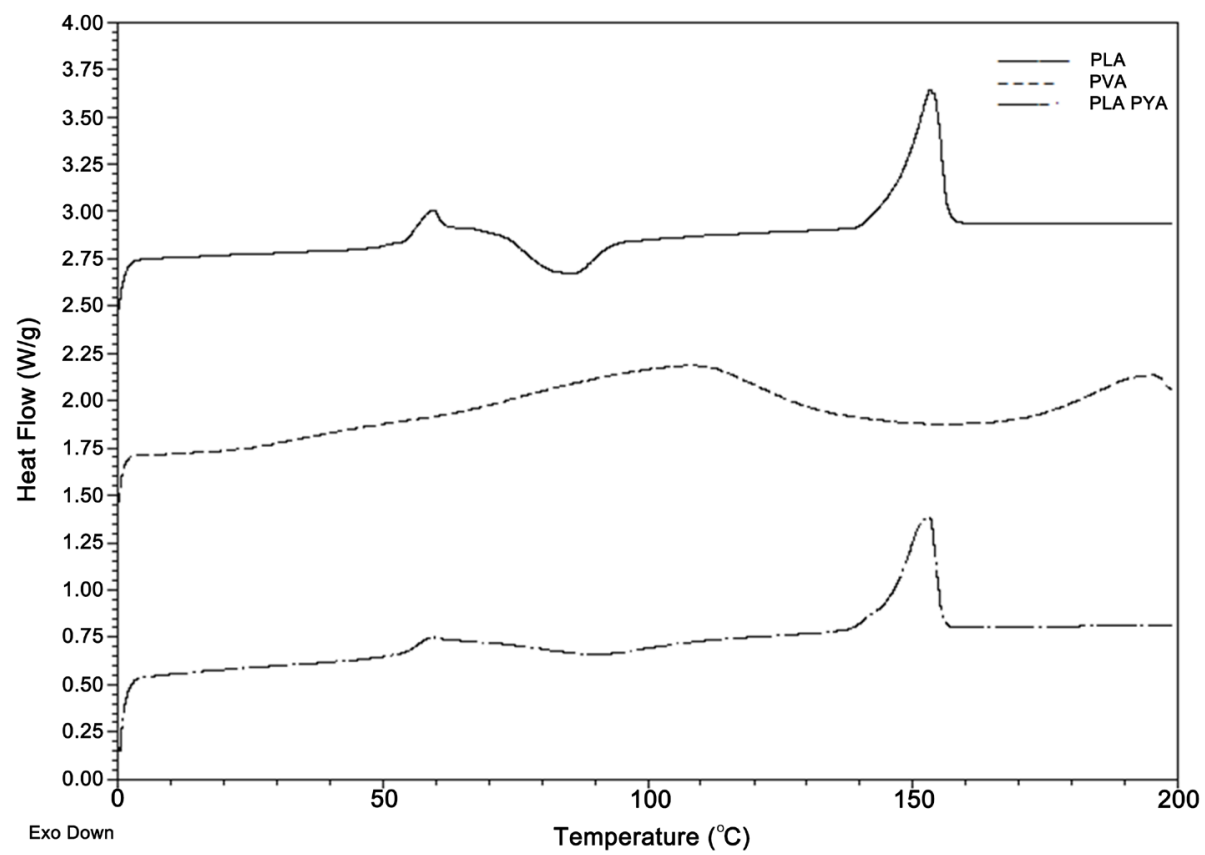

Figure 9. DSC traces of monolithic PVA and PLA and PVA/PLA core shell fibers.

\section{Conclusion}

In this work multifunctional polymer systems based on membranes formed by ultrafine PVA-PLA fibers with core-shell morphology were obtained by coaxial electrospinning. The fibers are constituted by a PVA core and a PLA shell which have some crystallinity and, in some cases, certain porosity, which is dependent on the electrospinning condition. Nanofibers with average diameter of about $200 \mathrm{~nm}$ were obtained, but homogeneous morphology and smooth surface were only attained when the flow rate of the external PLA solution was 4 times the flow rate of the internal PVA solution. The increase in the PLA solution flow rate increases the diameter of the core-shell fiber reaching diameters from 1 to $2 \mu \mathrm{m}$. Membranes formed by these core-shell fibers presented contact angles slightly smaller than those observed for membranes of monolithic PLA fibers, demonstrating that these materials have an improved hydrophilicity, which made it with a good potential for application as biomaterials for controlled release of bioactive molecules.

\section{Acknowledgements}

The authors gratefully acknowledge the Brazilian Agencies CNPq, CAPES and FAPERJ for supporting this work.

\section{References}

[1] Li, D., Wang, Y. and Xia, Y. (2003) Electrospinning of Polymeric and Ceramic Nanofibers as Uniaxially Aligned Arrays, NanoLetters, 3, 1167-1171. http://dx.doi.org/10.1021/nl0344256

[2] Doshi, J. and Reneker, D.H. (1995) Electrospinning Process and Applications of Electrospun Fibers. Journal of Electrostatics, 35, 151-160. http://dx.doi.org/10.1016/0304-3886(95)00041-8

[3] Panseri, S., Cunha, C., Lowery, Carro, U.D., Taraballi, F., Amadio, S., Vescovi, A. and Gelain, F. (2008) Electrospun Micro- and Nanofiber Tubes for Functional Nervous Regeneration in Sciatic Nerve Transections. BMC Biotechnology, 8, 1-12. http://dx.doi.org/10.1186/1472-6750-8-39

[4] Wang, C.Y., Liu, J.J., Fan, C.Y., Mo, X.M., Ruan, H.J. and Li, F.F. (2012) The Effect of Aligned Core-Shell Nanofibres Delivering NGF on the Promotion of Sciatic Nerve Regeneration. Journal of Biomaterials Science, 23, 167-184. http://dx.doi.org/10.1163/092050610X545805

[5] Greiner, A. and Wendorff, J. (2007) Electrospinning: A Fascinating Method for the Preparation of Ultrathin Fibers. Angewandte Chemie International, 46, 5670-5703. http://dx.doi.org/10.1002/anie.200604646

[6] Yu, J.H., Fridrikh, S.V. and Rutledge, G.C. (2004) Production of Submicrometer Diameter Fibers by Two-Fluid Elec- 
trospinning. Advanced Materials. 16, 1562-1566. http://dx.doi.org/10.1002/adma.200306644

[7] Yarin, A.L. (2010) Coaxial Electrospinning and Emulsion Electrospinning of Core-Shell Fibers. Polymers Advanced Technologies, 22, 310-317. http://dx.doi.org/10.1002/pat.1781

[8] McCann, J.T., Li, D. and Xia, Y. (2005) Electrospinning of Nanofibers with Core-Sheath, Hollow, or Porous Structures. Journal of Materials Chemistry, 15, 735-738. http://dx.doi.org/10.1039/b415094e

[9] Le, V.T., Kim, H., Ghosh, A., Kim, J., Chang, J., Vu, Q.A., Pham, D.T., Lee, J.H., Kim, S.W. and Lee, Y.H. (2013) Coaxial Fiber Supercapacitor Using All-Carbon Material Electrodes, ACS Nano, 7, 5940-5947. http://dx.doi.org/10.1021/nn4016345

[10] Yu, D.G., Yu, J.H., Chen, L. Williams, G.R. and Wang, X. (2012) Modified Coaxial Electrospinning for the Preparation of High-Quality Ketoprofen-Loaded Cellulose Acetate Nanofibers. Carbohydrate Polymers, 90, 1016-1023. http://dx.doi.org/10.1016/j.carbpol.2012.06.036

[11] Liao, I.-C. and Leong, K.W. (2011) Efficacy of Engineered FVIII-Producing Skeletal Muscle Enhanced by Growth Factor-Releasing Co-Axial Electrospun Fibers. Biomaterials, 32, 1669-1677. http://dx.doi.org/10.1016/j.biomaterials.2010.10.049

[12] Rubert, M., Dehli, J., Li, Y.F., Taskin, M.B., Xu, R., Besenbacher, F. and Chen, M. (2014) Electrospun PCL/PEOCoaxial Fibers for Basic Fibroblast Growth Factor Delivery. Journal of Materials Chemistry B, 2, 8538-8546. http://dx.doi.org/10.1039/C4TB01258E

[13] Huang, R., Long, Y.Z., Tang, C.C. and Zhang, H.D. (2013) Fabrication of Nano-Branched Coaxial Polyaniline/Polyvinylidene Fluoride Fibers via Electrospinning for Strain Sensor. Advanced Materials Research, 853, 79-82.

[14] Dzenis, Y. (2004) Spinning Continuous Fibers for Nanotechnology. Science, 304, 1917-1919. http://dx.doi.org/10.1126/science.1099074

[15] Pham, Q.P., Sharma, U. and Mikos, A.G. (2006) Electrospinning of Polymeric Nanofibers for Tissue Engineering Applications: A Review. Tissue Engineering, 12, 1197-1211. http://dx.doi.org/10.1089/ten.2006.12.1197

[16] Park, J.-C., Ito, T., Kim, K.-O., Kim, K.-W., Kim, B.-S., Khil, M.-S., Kim, H.-Y. and Kim, I.-S. (2010) Electrospun Poly(Vinyl Alcohol) Nanofibers: Effects of Degree of Hydrolysis and Enhanced Water Stability. Polymer Journal, 42, 273-276. http://dx.doi.org/10.1038/pj.2009.340

[17] Zhang, C., Yuan, X.Y., Wu, L.L., Han, Y. and Sheng, J. (2005) Study on the Morphology of Electrospun Poly(Vinyl Alcohol) Fiber Mat. European Polymer Journal, 41, 423-432. http://dx.doi.org/10.1016/j.eurpolymj.2004.10.027

[18] Ribeiro, C.,Sencadas, V., Caparros, C., Ribelles, J.L.G. and Lanceros-Méndez, S. (2012) Fabrication of Poly(Lactic Acid)-Poly(Ethylene Oxide) Electrospun Membranes with Controlled Micro to Nanofiber Sizes. Journal of Nanoscience and Nacotechnology, 12, 6746-6753. http://dx.doi.org/10.1166/jnn.2012.4544

[19] Kanani, A.G. and Bahrami, S.H. (2011) Effect of Changing Solvents on Poly( $\varepsilon$-Caprolactone) Nanofibrous Webs Morphology. Journal of Nanomaterials. http://dx.doi.org/10.1155/2011/724153

[20] Gu, X.H., Song, X., Shao, C.H., Zeng, P., Lu, X.K., Shen, X.Y. and Yang, Q. (2014) Electrospinning of Poly(Butylene-Carbonate): Effect of Solvents on the Properties of the Nanofibers Film. International Journal of Electrochemical Science, 9, 8045-8056. http://www.electrochemsci.org/papers/vol9/91208045.pdf

[21] Qin, X.H. and Wu, D.Q. (2012) Effect of Different Solvents on Poly (Caprolactone) (PCL) Electrospun Nonwoven Membranes. Journal of Thermal Analysis and Calorimetry, 107, 1007-1013. http://dx.doi.org/10.1007/s10973-011-1640-4

[22] Srinivasarao, Y., Marquez, M. and Thorsen, T. (2007) Multijet Electrospinning of Conducting Nanofibers from Microfluidic Manifolds. Journal of Applied Polymer Science, 106, 3171-3178.

[23] Megelski, S., Stephens, J.S., Chase, D.B. and Rabolt, J.F. (2002) Micro- and Nanostructured Surface Morphology on Electrospun Polymer Fibers. Macromolecules, 35, 8456-8466. http://dx.doi.org/10.1021/ma020444a

[24] Zander, N. (2013) Hierarchically Structured Electrospun Fibers. Polymers, 5, 19-44. http://dx.doi.org/10.3390/polym5010019

[25] Havrdova, M., Polakova, K., Skopalik, J., Vujtek, M., Mokdad, A., Homolkova, M., Tucek, J., Nebesarova, J. and Zboril, R. (2014) Field Emission Scanning Electron Microscopy (FE-SEM) as an Approach for Nanoparticle Detection Inside Cells. Micron, 67, 149-154. http://dx.doi.org/10.1016/j.micron.2014.08.001

[26] Kempen, P.J., Kircher, M.F., Zerda, A., Zavaleta, C.L., Jokerst, J.V., Mellinghoff, I.K., Gambhir, S.S. and Sinclair, R. (2015) A Correlative Optical Microscopy and Scanning Electron Microscopy Approach to Locating Nanoparticles in Brain Tumors. Micron, 68, 70-76. http://dx.doi.org/10.1016/j.micron.2014.09.004

[27] Nagle, D.J., George, G.A., Rintoul, L. and Fredericks, P.M. (2010) Use of Micro-ATR/FTIR Imaging to Study Heterogeneous Polymer Oxidation by Direct Solvent Casting onto the ATR IRE. Vibrational Spectroscopy, 53, 24-27. http://dx.doi.org/10.1016/j.vibspec.2010.01.018 
[28] Schwarz, J.C., Pagitsch, E. and Valenta, C. (2013) Comparison of ATR-FTIR Spectra of Porcine Vaginal and Buccal mucosa with Ear Skin and Penetration Analysis of Drug and Vehicle Components into Pig Ear. European Journal of Pharmaceutical Sciences, 50, 595-600. http://dx.doi.org/10.1016/j.ejps.2012.12.020

[29] Peresin, M.S., Habibi, Y., Zoppe, J.O., Pawlak, J.J. and Rojas, O.J. (2010) Nanofiber Composites of Polyvinyl Alcohol and Cellulose Nanocrystals: Manufacture and Characterization. Biomacromolecules, 11, 674-681. http://dx.doi.org/10.1021/bm901254n

[30] Inai, R., Kotaki, M. and Ramakrishna, S. (2005) Structure and Properties of Electrospun PLLA Single Nanofibers. Nanotechnology, 16, 208-213. http://dx.doi.org/10.1088/0957-4484/16/2/005 
Scientific Research Publishing (SCIRP) is one of the largest Open Access journal publishers. It is currently publishing more than 200 open access, online, peer-reviewed journals covering a wide range of academic disciplines. SCIRP serves the worldwide academic communities and contributes to the progress and application of science with its publication.

Other selected journals from SCIRP are listed as below. Submit your manuscript to us via either submit@scirp.org or Online Submission Portal.
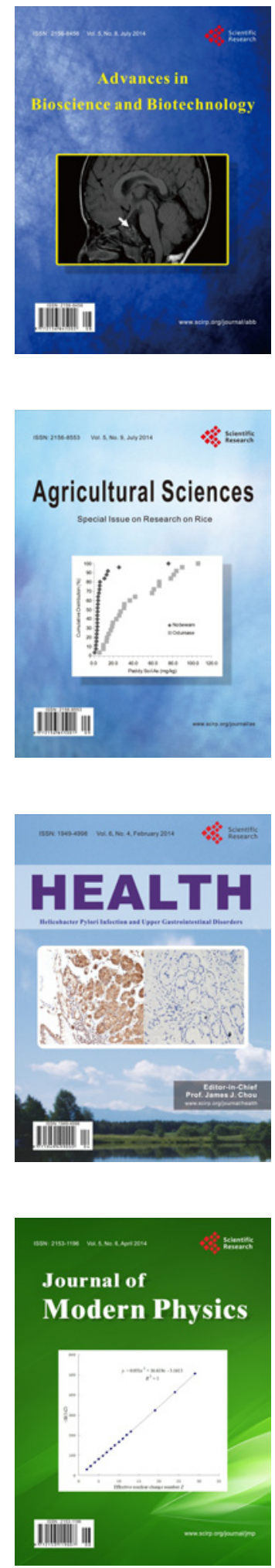
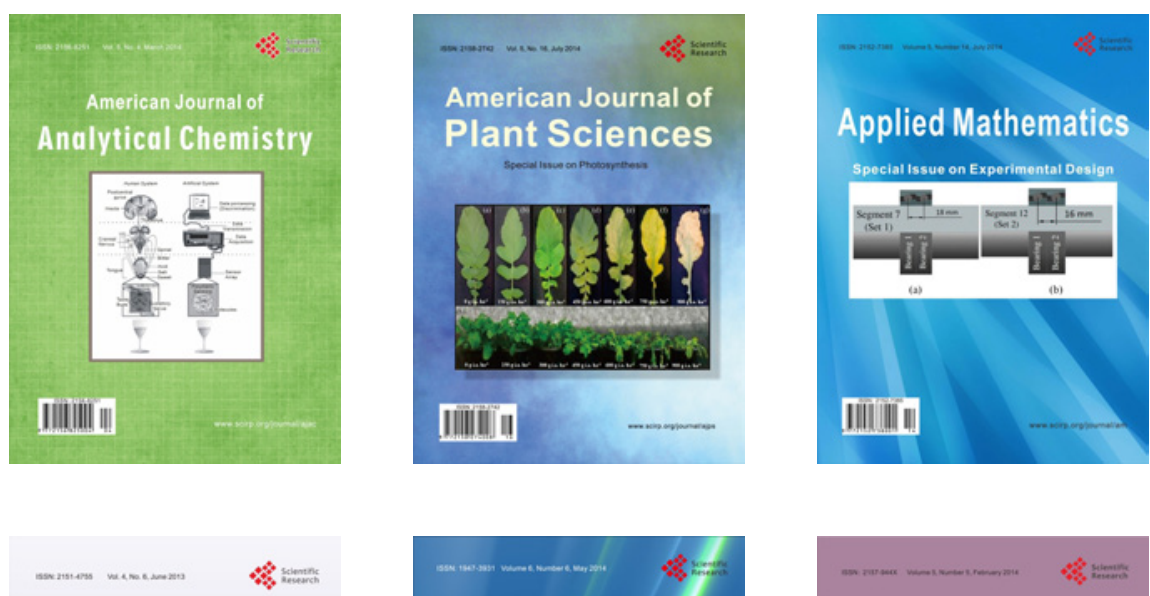

Creative Education
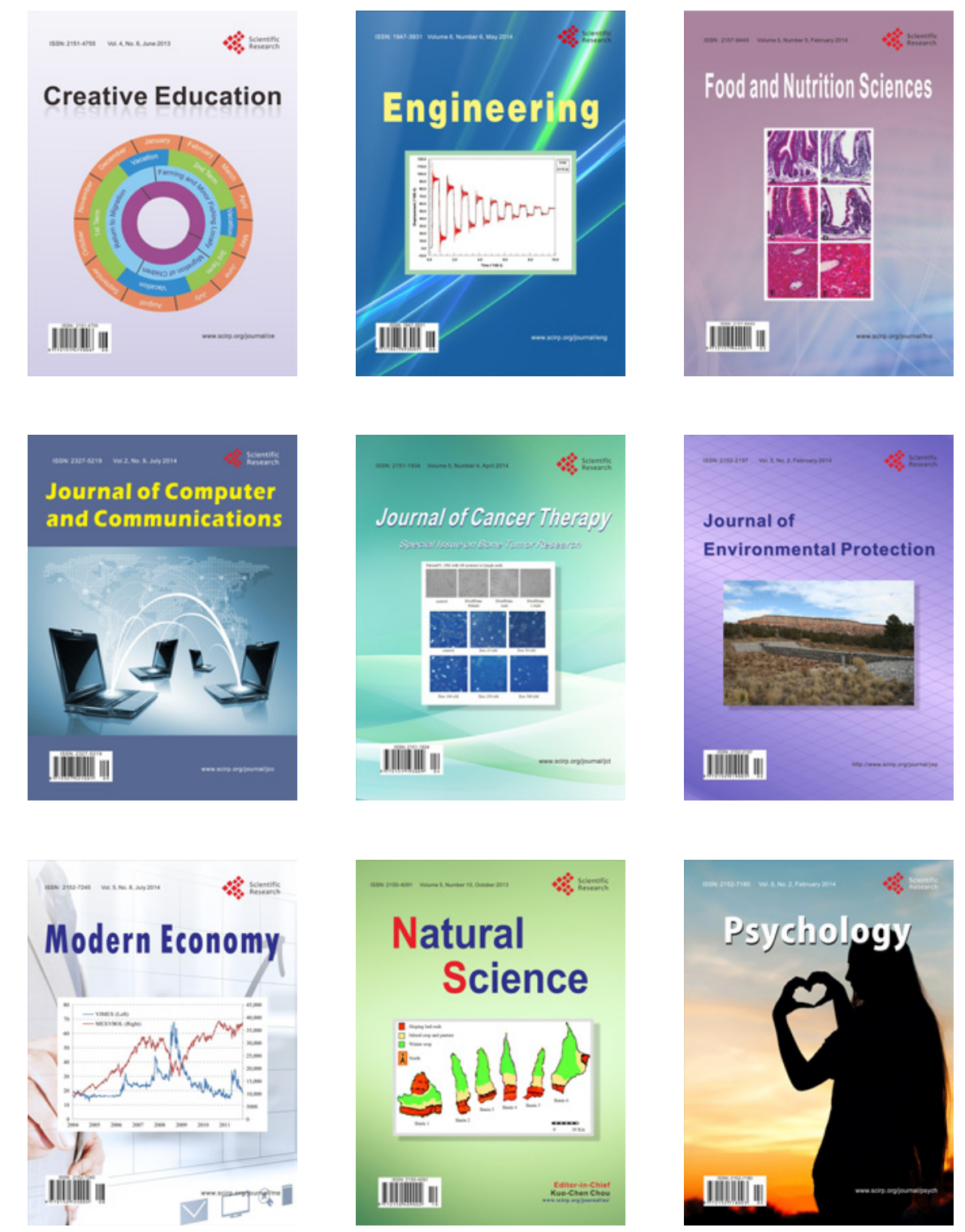